\title{
Expanding the notion of addressing relations
}

\author{
Rufus H. Gouws
}

Received: 12 May 2014/ Accepted: 7 December 2014/Published online: 6 January 2015

(C) Springer Berlin Heidelberg 2014

\begin{abstract}
This paper offers a discussion of various aspects of the notion of addressing and addressing relations in dictionaries. Reference is made to the way in which these terms are defined and used in metalexicographic literature. It is shown how the metalexicographer Herbert Ernst Wiegand has introduced these terms and how he uses them in his meticulously designed general theory of lexicography. Maintaining the approach and interpretations used by Wiegand, it is emphasised that the notion of addressing could also be used in an expanded way to include more than only items as addressed entries and to accommodate non-condensed entries as participants in addressing relations. Using examples from existing dictionaries, the use of pictorial illustrations and article boxes to convey data directed at lemmatic and non-lemmatic entries is discussed to show their participation in lexicographic relations where a form and information related to that form are brought together. Some aspects of treatment relations in online dictionaries are identified to illustrate the need for a more comprehensive interpretation of addressing relations. Finally, suggestions are made for a distinction between different types of addressing.
\end{abstract}

Keywords Addressing - Addressing relation - Article box · Pictorial illustration · Primary addressing $\cdot$ Secondary addressing

\section{Introduction}

In their discussion of different components, parts and structures of monolingual dictionaries Hausmann and Wiegand (1989: 328) introduced the notion of addressing, addressing relations and addressing structures in dictionaries. Although addressing is a lexicographic procedure without which dictionary articles in their

R. H. Gouws ( $\square)$

University of Stellenbosch, Stellenbosch, South Africa

e-mail: rhg@sun.ac.za 
default lexicographic presentation could not be interpreted in a clear and an unambiguous way, limited attention has been given to this concept in theoretical discussions. In a number of discussions, Wiegand has elaborated on the initial discussion found in Hausmann and Wiegand (1989) and Wiegand (1989). Wiegand (2006) gives a thorough account of the concept of addressing in printed dictionaries with Wiegand (2011) focusing on addressing in both mono- and bilingual dictionaries. Wiegand and Gouws (2013) present the latest developments regarding this aspect of lexicographic theory and practice. Other publications dealing with specific interpretations and applications of the addressing concept include (Gouws 1994), Louw and Gouws (1996) and Gouws and Prinsloo (2005).

Hausmann and Wiegand (1989: 328) start their discussion by saying that the basic unit of a dictionary is the treatment unit and this unit results

"when a form mentioned and information relating to that form are brought together. The relation of form and information is that of topic and comment."

According to the basic notion of addressing and addressing structures, the way in which a form and information related to that form are brought together is the addressing procedure, cf. Hausmann and Wiegand (1989: 328). They say that each information item in a dictionary article is addressed to a form and that form is called the address. It is important to note here that the carrier of the information that is addressed to a form is an item. According to Wiegand and Smit (2013: 153):

"An item is a functional text segment without the status of a sentence but with the status of a text segment which is given as a discernable item form assigned with at least one genuine function, the latter being precisely such that a user can obtain knowledge about the item's subject as lexicographical information."

One of the core features of addressing, as found in more recent publications by Wiegand, resides in the point of departure that addressing relations only prevails in condensed dictionary articles. In this regard, Wiegand and Gouws (2013: 273) say:

"In non-condensed dictionary articles ... there are no addressing relations.

This also applies to the other non-condensed accessible entries."

In this paper, the discussion will focus on the approach to restrict the concept of addressing to condensed and partially condensed articles. In this regard, it will be shown that non-condensed entries, included as part of the treatment of a given form, also are directed at that form and participate in a relation to that form. The prevailing discussion of addressing has only dealt with printed dictionaries. The need to re-interpret the notion of addressing primarily follows from the emergence of online lexicography. Looking at online dictionaries, it is not always clear to what extent the default approach to addressing is still valid. Consequently, in this regard, this paper will also pay limited attention to certain aspects of online dictionaries. A proposal will be made for a broader interpretation of the notion of addressing and a distinction between different procedures of addressing.

This paper is broadly written within the framework of a general theory of lexicography, as formulated over many years in numerous publications by the 
German lexicographer Herbert Ernst Wiegand. A significant feature of this theory lies in approaching a dictionary as a carrier of text types, exhibiting various structures with different relations between these structures. Addressing is one of these relations.

\section{Addressing in condensed articles}

Although Hausmann and Wiegand (1989) make no reference to either condensed or non-condensed articles in their discussion of addressing, Wiegand (1989: 445) does refer to it when saying that a lemma is the reference object of "verdichtete sprachreflexive Prädikationen ..." (condensed language-reflexive predications). In terms of Wiegand (2006: 190), an active dictionary user can retrieve the necessary information from an item where that information is given by the mere mentioning of the lemma form, e.g. information regarding the spelling of the lemma sign. By merely looking at the lemma sign goat in the following partial article from the American Heritage Dictionary (AHD), the user can retrieve information regarding the spelling of the word represented by the lemma sign:

goat

ruminant mammal with hollow horns and coarse hair belonging to the genus

Capra of the cattle family and closely related to the sheep....

\section{Example 1 from the AHD}

Wiegand (2006: 190) argues that an active dictionary user cannot always retrieve the needed information by merely looking at a single item-even an item carrying the relevant data. The successful retrieval of information follows from an item pair that contains the item giving the relevant data as well as the item at which the specific data-carrying item is directed. In the following partial article of the lemma sign masels (=measles) from the monolingual Afrikaans dictionary Woordeboek van die Afrikaanse Taal (WAT) the item slegs i.d. $m v$. (only in the plural) cannot be consulted in isolation to successfully retrieve the information conveyed by this item.

masels s.nw. (slegs i.d. mv.)

1a Hoogs aansteeklike virussiekte met 'n broeitydperk van 10 tot 14 dae, wat veral kinders aantas, en....

\section{Example 2 from the WAT}

This item is directed at the lemma sign masels and the knowledgeable user will relate this information to the lemma sign to retrieve the information that the lemma sign represents the word masels that is only used in the plural form. In terms of Wiegand (2006), the retrieval of information succeeds by means of the item pair $<$ masels, slegs i.d. mv.>. The relation between "masels" and "slegs i.d. mv." as established by the lexicographer and reconstructed by the active user in the process of information retrieval as a directed relation is known as an addressing relation in which the relation holds that " $x$ is addressed at $y$ ", with " $x$ " being a variable for addressed functional text segments and " $y$ " a variable for addresses. These addresses are also known as reference addresses, cf. Wiegand (2011). In the given 
example, slegs i.d. mv. is addressed at masels and therefore, is known as the addressed item whereas masels is the address and therefore, the non-addressed item.

According to Wiegand and Gouws (2013: 276):

"addressing relations are a lexicographic substitute for the missing natural language syntactic relations. Therefore addressing relations should not be expected when item texts occur because they display natural language syntax."

Due to the non-natural syntax found in many dictionary articles, dictionary users cannot retrieve information from items without relating them to a previously mentioned item, typically the lemma. This relation between an item and the lemma or the item at which the given item is directed makes it possible to successfully retrieve the information from the data on offer in the dictionary article. The articles of the lemma hut in the AHD and the online Oxford Dictionaries (OD) contain the following items giving the paraphrase of meaning:

A crude or makeshift dwelling or shelter;... (AHD)

Example 3 from the AHD

A small, simple, single-storey house or shelter (OD)

\section{Example 4 from the OD}

These items are condensed and they do not display full sentences in natural syntax. They are syntactic fragments conveying the required data. By merely looking at these paraphrases of meaning without knowing the lemma at which they are addressed one can hardly relate these paraphrases of meaning to the appropriate word of which they present the meaning. However, the combination of the lemma and the paraphrase of meaning make an unambiguous retrieval of the meaning possible. Between the lemma and the paraphrase of meaning there is an addressing relation, linking the addressed item to its address. Compare the preceding partial articles with the partial article from COBUILD for the lemma sign hut:

A hut is a small house with only one or two rooms, especially one which is made of wood, mud, grass, or stones.

\section{Example 5 from COBUILD}

Whereas the items in examples 3 and 4 are part of articles characterised by being texts

"in a genuine lexicographic text format in which comments are made in a nonnatural way regarding at least one natural language",

cf. Wiegand and Gouws (2013: 273), example 5 is a part of a dictionary article presented in a natural and non-condensed way in terms of its syntax. This entry, a paraphrase of meaning, is not an item but rather an item text. In the dictionary article, the user does not have to link this entry to the lemma to achieve an optimal retrieval of the information regarding the meaning of the word represented by the lemma sign. No relation has to be established to substitute missing natural language syntactic relations and therefore, this example does not display an addressing relation. Even without an addressing relation, the reference of the sentence 
functioning as item text is quite clear, cf. also Wiegand (2011). Addressing relations do not prevail when item texts are entered in dictionary articles because natural syntax is displayed. Wiegand and Gouws (2013: 273) maintain that in printed dictionaries:

"textual condensation and the accompanying non-naturalness of the lexicographic texts form the two related prerequisites for specific text-syntactic relations, known as addressing relations that are necessarily implemented in order to ensure an organised recording of lexicographic information that can be learned by the user."

Consequently, although Hausmann and Wiegand (1989) made no reference to textual condensation, the development since then in the discussion of addressing has established this concept as applicable only in dictionary articles that display either full or partial textual condensation, and only a condensed entry in a dictionary article can be regarded as being addressed and can have an addressing relation with another entry in that dictionary article.

Since Hausmann and Wiegand (1989) and in the subsequent publications dealing with addressing, provision has been made for different types of addressing in terms of the article-internal status of the item functioning as address. The majority of addressing relations are examples of lemmatic addressing with the relevant item being addressed at the lemma sign. Articles can also display relations of sublemmatic addressing with a sublemma being the address or even non-lemmatic addressing where one finds an item other than a lemma or sublemma, usually a microstructural item, functioning as address.

Besides addressing relations Wiegand (2011) also makes provision for other relations, e.g. the item relation, the reference address relation, the treatment relation, the mentioning relation. This is done to ensure a clear distinction between addressing and other textual relations. For the purpose of this paper, the treatment relation should also be mentioned. Following Wiegand (2011) one can distinguish the reference addressing relation $<$ masels, slegs i.d. $m v .>$, where a relation between the lemma and an item is postulated, from a unit like $<$ masels, slegs i.d. mv. $>$ where a relation is postulated between the word masels, lexicographically represented by the lemma sign, and an entry presented as part of the treatment of this word, indicating that the word masels is only used in the plural form. This is known as a treatment relation and a unit like $<$ masels, slegs i.d. mv. $>$ is a lexicographical treatment unit.

\section{Treatment and addressing}

As indicated earlier Hausmann and Wiegand (1989: 328) regard the treatment unit as the basic unit of a dictionary. According to them, this is the result of bringing a form that has been mentioned and information related to that form together. This results in a treatment relation but the way in which the bringing together of a form and information related to that form occurs, can result in an addressing relation. The realisation of this relation depends on the nature of the entry carrying the data. If 
that entry is a result of textual condensation it qualifies to be an item and thus to participate in an addressing relation with the form at which it is addressed. If it is not a result of textual condensation, it does not qualify as an item and therefore also not as a participant in the relation of addressing.

In metalexicographic literature, the notion of a treatment unit has not been defined or discussed in a comprehensive way. Treatment units realise treatment relations and the prevailing relation within treatment units can be formalised as " $x$ is lexicographically treated by $y$ ", where " $y$ " is a variable within a dictionary article entered as part of the treatment of another variable " $x$ ". Where the treatment unit consists of e.g. a word represented by the lemma and an item giving the paraphrase of meaning an addressing relation prevails within the treatment unit between the lemma and the item giving the paraphrase of meaning. An implication of this approach is that where a form and information related to that form but presented as an item text and not as an item are brought together then, contrary to Hausmann and Wiegand (1989: 329), the way in which these entries are brought together do not constitute an addressing procedure.

It is clear that an item that is the result of textual condensation has a different type of relation to the item at which it is directed compared to an item text that is not the result of a procedure of textual condensation. A question that can be raised is whether the notion of addressing should not be interpreted in a wider sense to make provision for addressing procedures that include both items and other entries participating in a relation between form and information related to and directed at that form.

In the following section, some dictionary entries in dictionary articles will be discussed to try and find an answer to this question.

\section{Different types of data}

According to Wiegand and Gouws (2013: 275), when looking at lexicographic data one can distinguish between text data and pictorial data. Whether the use of pictorial data in a dictionary article form part of procedures of addressing needs to be clarified. The same applies to data presented in so-called text boxes (Gouws and Prinsloo 2010), infoboxes, infowindows (Wiegand 2006: 215) or article windows (Wiegand and Gouws 2011: 287).

\subsection{Pictorial illustrations}

Pictorial illustrations are used in a variety of ways in different dictionary types. Discussions of the use of pictures in dictionaries can be found in among others AIKasimi (1977), Hancher (1988), Hupka (1989) and Stein (1991). When evaluating the use of pictorial illustrations, one has to distinguish between a functional and a non-functional use. In a non-functional use the pictures might have a cosmetic value but they do not contribute to achieving the genuine purpose of the specific dictionary. Where pictorial illustrations are used in a functional way they are integrated into the genuine purpose of the dictionary and they convey data from 
which the user retrieves information to enhance the quality of the dictionary consultation procedure. They help with an optimal retrieval of information. Pictorial illustrations are used in both printed and online dictionaries. The following screenshot from the AHD presents part of an article nest where each nested article contains a picture displaying the object to which the lemma sign refers:

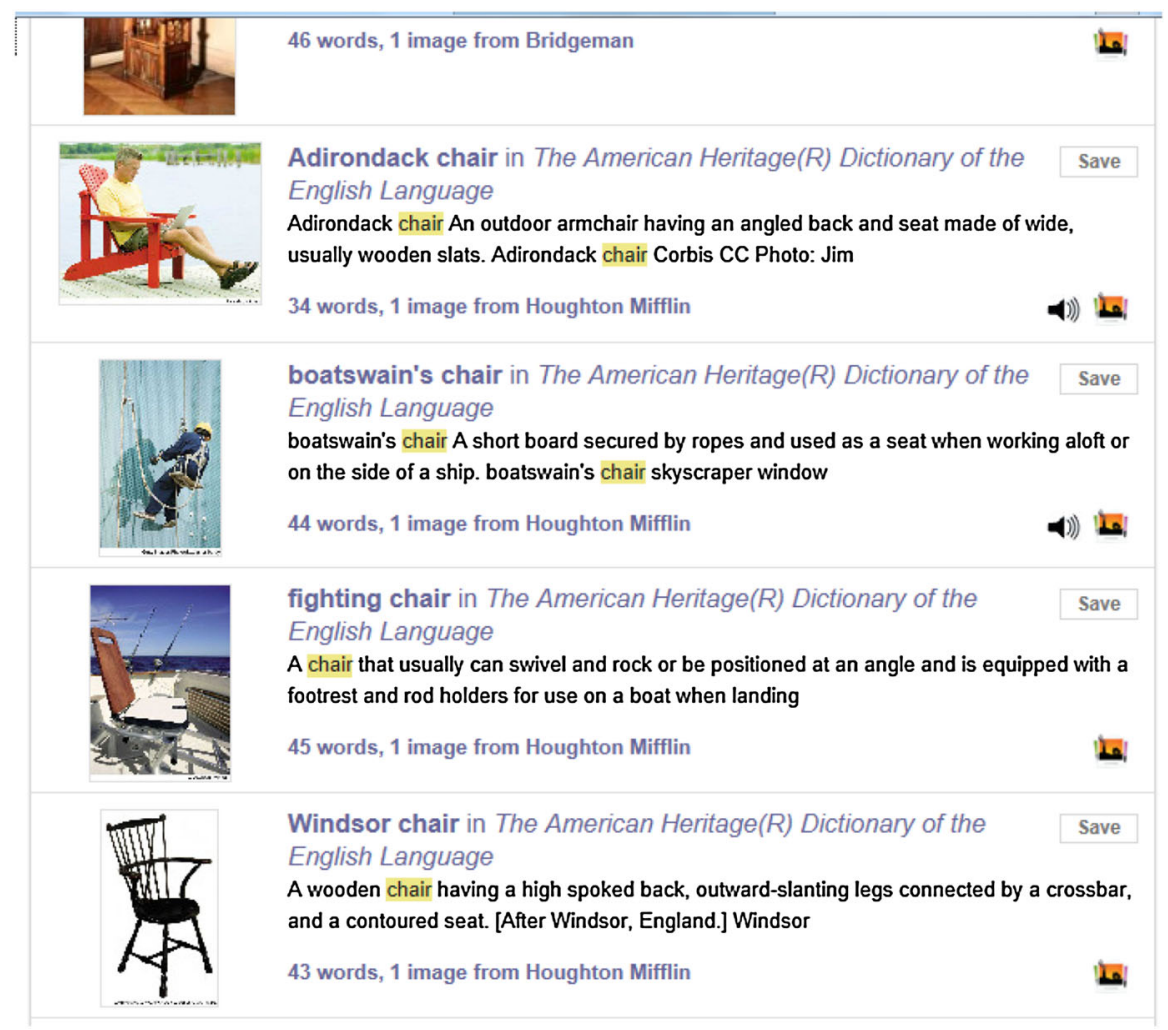

\section{Example 6 from the AHD}

In each one of these articles, the pictures enhance the quality of the lexicographic treatment due to their contribution to a better information transfer. All these pictorial illustrations are directed at the relevant lemma sign.

In monolingual dictionaries, pictures are typically used to illustrate the object to which the word represented by the lemma sign refers, either to reflect on the full meaning of the word or to distinguish between its polysemous senses. In bilingual dictionaries pictorial illustrations either help with the comprehension of the source language form or with an unambiguous interpretation of one or more translation equivalents. AI-Kasimi (1977: 100) gives a number of reasons for the functional use of pictorial illustrations in dictionaries, e.g. a rapid retrieval of semantic information, where the verbal definition would be uneconomical, where a picture displays more distinctive features than a verbal form and where a picture gives a 
more comprehensible presentation due to some spatial relations that cannot be expressed so easily by an exclusively verbal account. Gouws and Prinsloo (2014) also indicate the need to use pictorial illustrations in dictionaries to convey cultural data. This is especially important in bilingual dictionaries where cultural differences between the two speech communities compel more than a mere verbal equivalent to ensure a successful dictionary consultation procedure.

In the elexiko online dictionary, pictorial illustrations are used to illustrate and to concretise. These illustrations are often directed at a single sense of the word represented by the lemma sign and they are given to enable an impression of the concrete form of that word. The lemma allee (="avenue" or "allee", i.e. "a street lined on both sides with trees") gets the following pictorial illustrations:

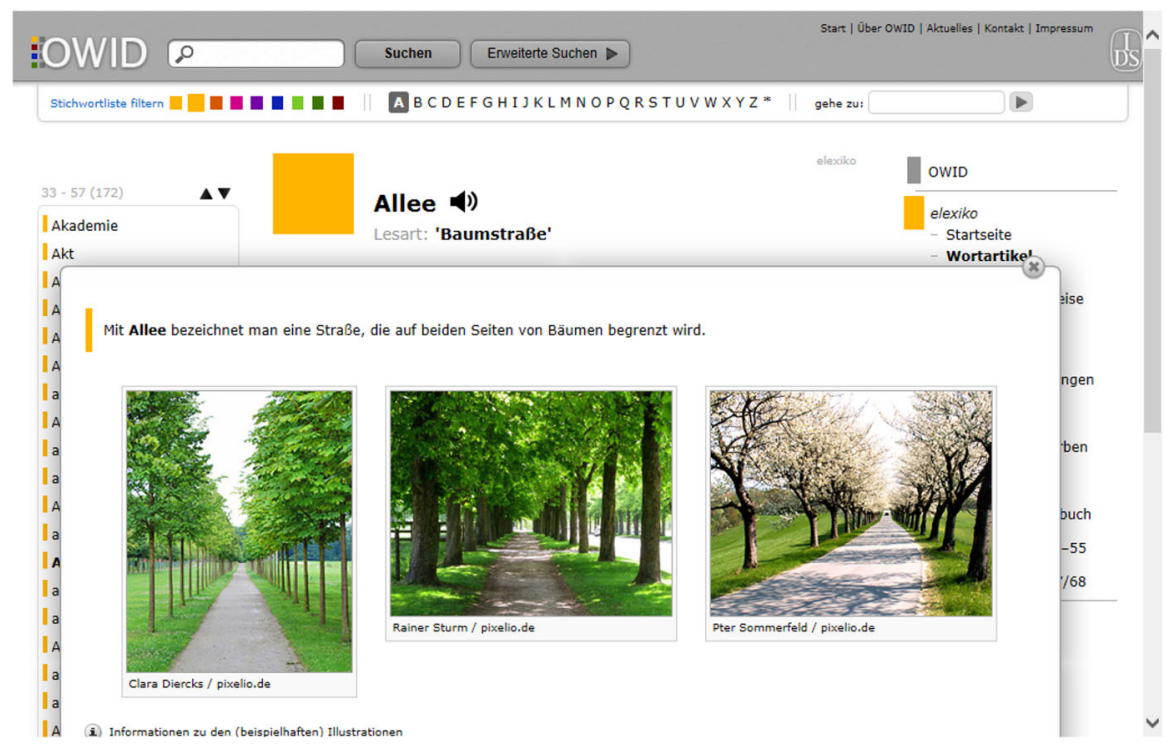

\section{Example 7 from elexiko}

The lemma and the relevant paraphrase of meaning, an item text, are repeated in this screenshot that displays one of the partial article structures of the lemma allee. The pictures are the main focus in this partial article; they are presented as part of the treatment of the word allee but there is no explicit link to say a given picture illustrates an alley. However, their position in the article leads the user to interpret them as being directed at the lemma sign. This lack of an explicit link can also be regarded as a form of unnatural or condensed cohesion that is not totally remote from the unnatural syntax prevailing in typical addressing relations.

In all these articles, the pictures play an important and functional role to help achieving the genuine function of the specific dictionary. They constitute an integral part of the treatment procedure and as entries within the article structure they are clearly directed at specific entries to enhance the understanding of the words represented by those entries. 
A question that springs to the mind is whether these pictorial illustrations participate in a procedure of addressing or merely in a treatment procedure? As seen in the preceding discussion, a procedure of addressing demands entries participating as addressed entries to function as items within the specific dictionary articles. A question to be raised is whether pictorial illustrations can be regarded as items?

Pictorial illustrations obey all the demands of this definition with the exception of being a "text segment" - if "text" is to be interpreted as "written material". If "text" has a broader interpretation, a pictorial illustration qualifies to be an item in a dictionary article. It has already been indicated that according to Wiegand and Smit (2013: 153):

"An item is a functional text segment without the status of a sentence but with the status of a text segment which is given as a discernable item form assigned with at least one genuine function, the latter being precisely such that a user can obtain knowledge about the item's subject as lexicographical information."

If the term text is a problem here one can always adjust the definition of an item by saying:

"An item is a functional text segment without the status of a sentence but with the status of a text segment or a functional article segment which is given as a discernable item form assigned with at least one genuine function, the latter being precisely such that a user can obtain knowledge about the item's subject as lexicographical information."

This would allow pictorial illustrations to fall within the scope of the concept of an item in a dictionary article.

However, when trying to determine whether they can participate in addressing relations an earlier mentioned statement by Wiegand and Gouws (2013: 273) demands that:

"textual condensation and the accompanying non-naturalness of the lexicographic texts form the two related prerequisites for specific text-syntactic relations, known as addressing relations that are necessarily implemented to ensure an organised recording of lexicographic information that can be learned by the user."

In their relation to e.g. a lemma or a non-lemmatic item pictorial illustrations do not adhere to either of the two prerequisites of textual condensation and the nonnaturalness of the lexicographic texts or the specific text-syntactic relations, albeit that they do participate in a different kind of non-natural "text-syntactic relation", i.e. a picture-word relation. Gouws (1994) referred to the use of pictorial illustrations as procedures of ostensive definitions, with the term ostensive implying that they define by means of showing the thing to which the word that has to be defined refers. Where these entries are used they constitute relations of what Gouws calls ostensive addressing, and these relations can be either of a lemmatic or a nonlemmatic nature. 
AI-Kasimi (1977: 98) allocates two functions to pictorial illustrations in bilingual dictionaries, i.e. they help with the capturing of the accompanying verbal translation equivalents and they serve as general examples to establish the concept that needs to be illustrated. This emphasises the functionality of pictorial illustrations and shows that they have much more than a mere cosmetic value. The functionality of pictorial illustrations also lies therein that they do not duplicate the data transfer but either complement or substitute the verbal presentation.

According to Hausmann (1977: 55) translation is not only of words but rather of words in specific contexts. In this regard, pictorial illustrations can play a role that is equally important as the role played by e.g. glosses or example sentences. Kromann et al. (1984: 188) argue that equivalence is a relation between the denotative, connotative and syntagmatic aspects of a lemma and the translation equivalent. Gouws (1994: 73) says that when giving a translation equivalent a lexicographer should be sure that the relation between lemma and translation equivalent satisfies these criteria. If the target language does not have a lexical item that can establish such a relation when employed as translation equivalent the lexicographer needs to supply additional assistance so that a relation of communicative equivalence, i.e. an equivalence relation that allows the user to select the translation equivalent and use it in an appropriate way in communication situations, can be achieved. Quite often a pictorial illustration can be used to supplement a translation equivalent to achieve communicative equivalence that would not have been possible without the use of the pictorial illustration.

The use of pictorial illustrations as integrated entries in the treatment process in bilingual dictionaries can also be motivated by the degree of translatability of a given word. The translatability of a word can be influenced by a variety of aspects. Barchudarow (1979: 55) indicates that different types of meaning have different grades of translatability, with referential meaning having the highest degree. A high degree of translatability alone does not imply that pictorial illustrations should not be used. When treating a polysemous lexical item with a high degree of translatability, additional entries are often needed to ensure the necessary semantic differentiation. In this regard, a functional use of pictorial illustrations can result in the best possible treatment of the lemma sign. Yet again these entries participate in a relation characterised by the bringing together of a form and information related to that form.

The lack of "text" and the lack of a traditional procedure of condensation disqualify pictorial illustrations from being participants in a default addressing relation.

The meticulous way in which Wiegand has defined and analysed the notion of addressing and the nature of addressing relations needs to be maintained. This also applies to his definition and analyses of treatment relations. However, although the use of pictorial illustrations as discussed in the preceding section does not meet the criteria of addressing relations the functional use of these entries should qualify them as participants in a relation where an entry is directly directed, i.e. addressed, at another entry. The bringing together of a form and information related to that form, presented as pictorial data, closely resembles a procedure of addressing: not only the translation equivalent but also the pictorial illustration must be related to 
the lemma sign so that the lexicographic information and the accompanying punctual knowledge regarding the appropriate target language item as translation equivalent of a given source language item becomes available, cf. also Wiegand (2011). Within metalexicographic terminology Wiegand's term address to indicate the entry at which an item is directed could also be useful and appropriate in other relations between a form and information related to that form without any evidence of textual condensation. This demands an expanded interpretation of the notion of addressing and not a substituting approach. This suggestion will be discussed in subsequent paragraphs.

\subsection{Article boxes}

In this paper, the term article box is used to refer to what is often called text boxes (Gouws and Prinsloo 2010) or article windows (Wiegand and Gouws 2011: 287). The term article box is preferred for various reasons. This term does not restrict the contents to a specific type of lexicographic data. The contents of these boxes are not always texts but they can also be populated by graphic or pictorial data. In such cases, the term text box would be less appropriate.

Article boxes can be inserted in different positions within the central list of a dictionary. One such position is as immediate constituent of an article stretch. Wiegand (2006: 215) also refers to these inserted texts as infowindows or infoboxes. The following excerpt included as framed inserted inner text in the Tweetalige aanleerderswoordeboek/Bilingual Learner's Dictionary (TAW) contains two rudimentary articles, with this framed box functioning as immediate constituent of the article stretch. This is an example of an article-external article box:

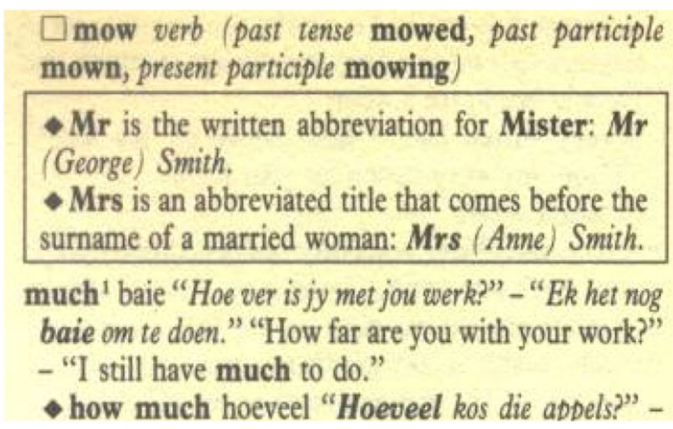

\section{Example 8 from TAW}

Another position in the central list where article boxes can be included is within dictionary articles, i.e. as immediate constituents of the relevant article and not of the article stretch, cf. the article of the lemma sign eie from the monolingual Afrikaans learners' dictionary Basiswoordeboek van Afrikaans (BWA) where an article box is given within the article, as postcomment to the first subcomment on 
semantics, and directed at one specific sense of the word represented by the lemma sign:

\begin{abstract}
eie (-) adj. (1) Eie benadruk dat iets aan 'n persoon of saak self behoort. 'n Mens moet self jou eie kinders straf. Dit is haar eie skuld dat sy laat by die werk opgedaag het. Amerika het genoeg van sy eie probleme.
\end{abstract}

In hierdie gebruik tree eie gewoonlik na 'n besitsvorm op.

(2) Eie beteken dat dit tipies van iemand of iets is. Baie mense sê die Suidoos is eie aan die Kaap. Pasta is iets wat eie is aan Italiaanse eetplekke. (3) Eie word gebruik om aan te toon dat iemand bloedfamilie is en nie aangetroude of stieffamilie nie. Sy is my eie niggie. Na sy eie ma se dood het sy pa weer getrou en die stiefma was vir hulle baie goed. UITDR.: lets op eie houtjie doen: Iets doen sonder om ander te raadpleeg. Sarel het op eie houtjie besluit om nie verder te studeer nie. eiegoed, eieliefde, eietyds

\section{Example 9 from BWA}

Article-internal boxes will be the focus of the present discussion with articleexternal boxes, i.e. inserted inner texts as immediate constituents of article stretches, falling beyond the scope of this discussion.

When looking at the way in which a form and information related to that form are brought together in a dictionary article one needs to take cognizance of the occurrence of article boxes. Wiegand and Gouws (2011: 287) maintain that article windows, the term they use, are not elements of the article constituent architecture or the article micro-architecture but they can be presented in article constituent architecture and micro-architecture images as part of enriched images. The articleinternal boxes they discuss come from the Oxford Advanced Learner's Dictionary of Current English $\left(\mathrm{OALD}^{8)}\right.$ and their judgement regarding the status of these article boxes is based on the following articles of the lemma signs able and satisfaction, (Wiegand and Gouws 2011:282): 


\begin{abstract}
able ow /'erbl/adj. $10 \mathrm{p} \sim$ to do sth (used as a modal verb) to have the skill, intelligence, opportunity, etc. needed to do sth: You must be able to speak French for this job. $\diamond A$ viral illness left her barely able to walk. $\odot$ I didn't feel able to disagree with him. $\diamond$ Will you be able to come? OPP unable $\$$ note at $\mathrm{CAN}^{1} \mathbf{2}$ (ablet /'erbla(r)/, iblest /'erblist/) intelligent; good at sth: the ablest student in the class $\diamond$ We aim to help the less able in society to lead an independent life. \$ see also ABLY
\end{abstract}

\section{sat.is.taction or /,sætis'fæksn/ noun}

1 on $[U, C]$ the good feeling that you have when you have achieved sth or when sth that you wanted to happen does happen; sth that gives you this feeling: to gain/get/derive satisfaction from sth $\diamond$ a look/smile of satisfaction - She looked back on her career with great satisfaction. $\diamond$ He had the satisfaction of seeing his book become a bestseller. $\diamond$ She didn't want to give him the satisfaction of seeing her cry. $\odot$ The company is trying to improve customer satisfaction. $\odot$ He was enjoying all the satisfactions of being a parent. $\Rightarrow$ see also DISSATISFACTION 2 [U] the act of FULFILLING a need or desire: the satisfaction of sexual desires $\diamond$ the satisfaction of your ambitions $\mathbf{3}[\mathrm{U}]$ (formal) an acceptable way of dealing with a complaint, a debt, an injury, etc: I complained to the manager but I

WORD FAMILY satisfaction noun ( $\neq$ dissatisfaction) satisfactory adj. ( $\neq$ unsatisfactory) satisfy verb satisfying adj. ( $\neq$ unsatisfying) satisfied adj. ( $\neq$ dissatisfied) $(\neq$ unsatisfied) didn't get any satisfaction.

tom to sb's satis faction 1 if you do sth to sb's satisfaction, they are pleased with it: The affair was settled to the complete satisfaction of the client. $\mathbf{2}$ if you prove sth to sb's satisfaction, they believe or accept it: Can you demonstrate to our satisfaction that your story is true?

\section{Example 10 from OALD ${ }^{8}$}

They (Wiegand and Gouws 2011: 281) describe these article windows as rectangular areas in which thematically related data are presented that stand in a relation to the lemma sign. With reference to the $\mathrm{OALD}^{8}$, they identify five possible positions for these boxes, i.e. north east, west, east, south west and south east (Wiegand and Gouws 2011: 284): 
(1)

\begin{tabular}{|c|c|}
\hline $\begin{array}{c}\text { (top } \\
\text { left) }\end{array}$ & $\begin{array}{c}\text { top } \\
\text { right }\end{array}$ \\
\hline $\begin{array}{c}\text { centre } \\
\text { left }\end{array}$ & $\begin{array}{c}\text { centre } \\
\text { right }\end{array}$ \\
\hline $\begin{array}{c}\text { bottom } \\
\text { left }\end{array}$ & $\begin{array}{c}\text { bottom } \\
\text { right }\end{array}$ \\
\hline
\end{tabular}

(2)

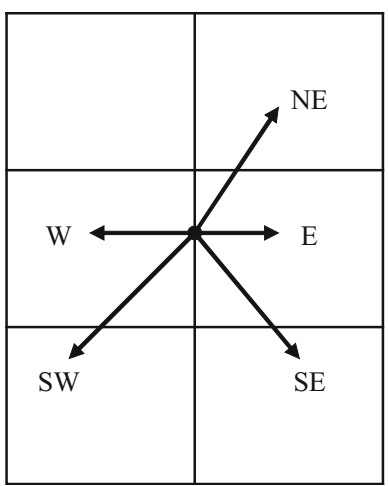

The position of the article windows in the $\mathrm{OALD}^{8}$ cannot always be regarded as comparable to the positions of article boxes in other dictionaries. Quite often a consistent positioning of article boxes, typically as postcomments, in specific article slots makes it possible to include them in procedures of functional positional segmentation. A systematic positioning of article boxes in fixed slots, e.g. at the end of a subcomment on semantics or at the end of the article, could qualify them as elements of the article constituent architecture or the article micro-architecture, i.e. as elements of a vertical article text architecture. This has implications for their possible participation in an expanded notion of addressing relations as will be seen in subsequent paragraphs.

\subsubsection{Types of article boxes}

Dictionary articles contain a variety of types of article boxes, cf. Gouws and Prinsloo (2010). Some article boxes have their own box-internal topic or title whereas others are without an explicit title and are rather directed at the topic or title of the dictionary article or a specific item in the article. The following article from the online Longman Dictionary of Contemporary English (LDOCE) contains an article box with its own topic, i.e. "Word choice", a subtopic "rent, hire, lease" and then seperate item texts dealing with the use of the words lease, rent and hire. 


\section{lease $\mathrm{e}^{2}$ verb}

\section{(Iㄴ) | MerL}

\section{lease [transitive]}

1 to use a building, car etc under a lease:

Im interested in leasing your cottage.

lease something from somebody

They lease the site from the council.

2 also lease out to let someone use a buildines car etc under a lease

lease something to somebody

The building was leased to a health club.

䜿 see usage note RERT $^{1}$

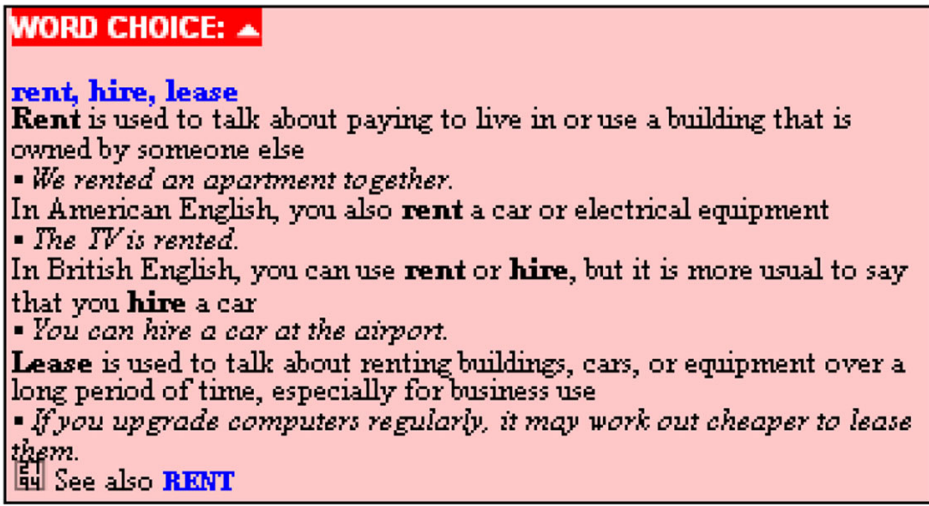

\section{Example 11 from the LDOCE}

In the article of the lemma sign complement the AHD contains an article box with the title "Usage note". The "Word choice" and "Usage note" article boxes have comparable presentations and approaches. As postcomments they contain data directed at aspects of the use of the word represented by the lemma sign of the article but also relating that word to one or more other words and giving illustrative examples. These entries, albeit that they occur in a box, are clearly directed at the lemma sign and by means of a remote relation also directed at other lemmata in the specific dictionaries, i.e. rent and hire in the LDOCE and compliment in the AHD. Louw and Gouws (1996) refer to this as a procedure of remote addressing: 
com'ple'ment (kǒm p1ə-mənt)

Share: If $y$ Tweet

n.

1.

a. Something that completes, makes up a whole, or brings to perfection: a sauce that is a fine complement to fish.

b. The quantity or number needed to make up a whole: shelves with a full complement of books.

c. The full crew of personnel required to run a ship.

d. Either of two parts that complete the whole or mutually complete each other.

2. An angle related to another so that the sum of their measures is $90^{\circ}$.

3. Grammar A word or words used to complete a predicate construction, especially the object or indirect object of a verb, for example, the phrase to eat ice cream in We like to eat ice cream.

4. Music An interval that completes an octave when added to a given interval.

5. Immunology A complex system of proteins found in normal blood plasma that combines with antibodies to destroy pathogenic bacteria and other foreign cells. Also called alexin.

6. Mathematics \& Logic For a universal set, the set of all elements in the set that are not in a specified subset.

7. A complementary color.

tr.v. (-mĕnt') com·ple-ment·ed, com·ple·ment-ing, com·ple·ments

To serve as a complement to: Roses in a silver bowl complement the handsome cherry table.

[Middle English, from Old French, from Latin complëmentum, from complēre, to fill out; see COMPLETE.]

Usage Note: Complement and compliment, though quite distinct in meaning, are sometimes confused because they are pronounced the same. As a noun, complement means "something that completes or brings to perfection" (The antique silver was a complement to the beautifully set table); used as a verb it means "to serve as a complement to." The noun compliment means "an expression or act of courtesy or praise" (They gave us a compliment on our beautifully set table), while the verb means "to pay a compliment to."

The American Heritage (3) Dictionary of the English Language, Fifth Edition copyright (e)2014 by

\section{Example 12 from the AHD}

Another type of article box with its own topic is found in the article of the lemma sign above in the CD ROM-version of the MacMillan English Dictionary (MED): 


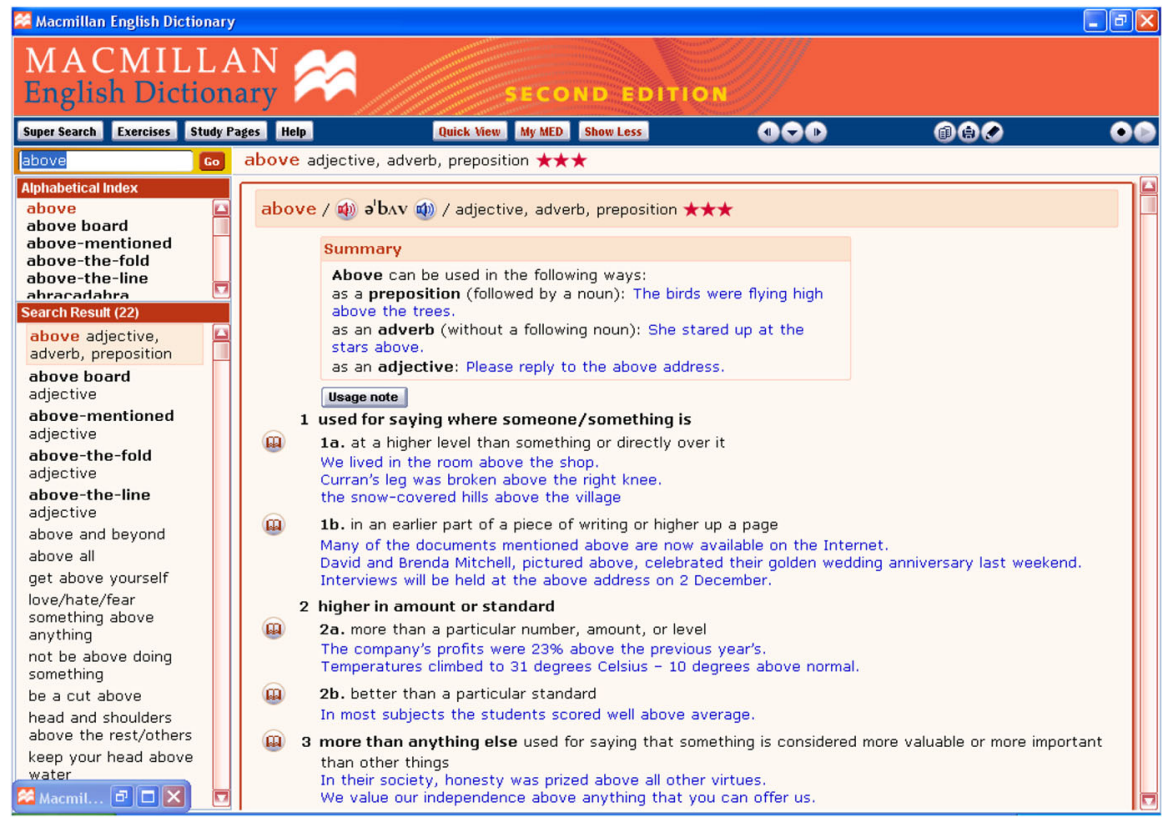

\section{Example 13 from the MED (CD ROM)}

The article box with the title "Summary" is a precomment to the comment on semantics. The title of the article box does not participate in the treatment procedures, but the remainder of the entries in the box does. This article box contains a summary of the main points dealt with in the article by capturing the use of the word represented by the lemma sign in its different part of speech occurrences. The item text and the example sentences are directed at the lemma sign that becomes the box-external but article-internal topic of the data in the article box. These entries in the article box give information related to a specific form, i.e. the lemma sign. In the online version of this dictionary, the same data is offered but not in a box but merely as a precomment to the comment on semantics, directed at the lemma sign and presented as part of its treatment, cf. the following screenshot: 


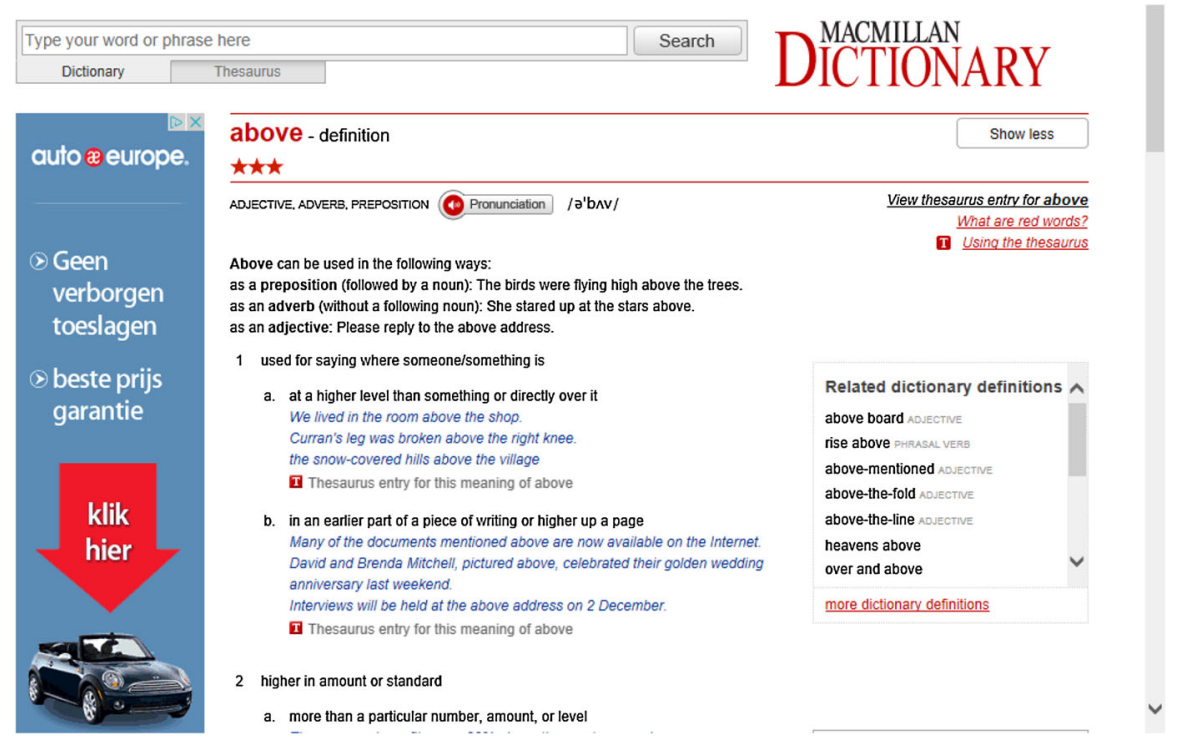

\section{Example 14 from the MED (online version)}

Groot woordeboek/Major Dictionary (GW), the bilingual dictionary with Afrikaans and English as treated language pair, does not contain items giving the pronunciation as default entries in its articles. When the lexicographer deems it is necessary to draw the user's attention to the pronunciation of a given word, these data are conveyed by means of entries in an article box, cf. the following excerpt from $\mathrm{GW}$ of the article of the lemma sign detail:

detaiĺ, (-s), detail; leeŕ, (ge-), detail, specify.

Die uitspraak is detai [ditai'].

\section{Example 15 from GW}

The article box contains an item text as non-condensed entry, presenting the pronunciation of the word represented by the lemma sign (=The pronunciation is detai [ditai]).The article of the lemma hartomleiding (=heart bypass) in the monolingual Afrikaans dictionary Handwoordeboek van die Afrikaanse Taal (HAT) includes an article box with data not exclusively directed at the word represented by the lemma sign. The entry in the article box rather indicates a word that people often incorrectly use instead of the word represented by the lemma sign (=The incorrect term hartomlyning (=heart lining) is often heard but should be avoided):

hart·om·lei-ding s.nw.

operasie waarby die bloedsomloop na die hart deur'n alternatiewe gang gelei word. 
Die foutiewe term hartomlyning word dikwels gehoor, maar moet vermy word.

\section{Example 16 from HAT}

These two article boxes do not have their own titles or topics and the contents form part of an extended treatment procedure, performed by adding item texts that convey relevant data. Yet again a form and information related to that form are brought together. Also in these articles, the article boxes are presented as postcomments.

The article-internal article boxes can be regarded as part of an extended obligatory microstructure. Going beyond the default items and item texts, they offer additional data deemed relevant by the lexicographer to assist the user in succeeding in an optimal retrieval of information from the dictionary article. In the articles, the boxed form is merely a means of presentation to draw the attention of the user to these additional non-default data entries. In example 15, the postcomment could have been given without the boxed form as an additional item text. The box does add to the salience of the entry, and albeit that the box itself is not a nontypographical structural indicator it does focus the attention of the user on the item text but not on a specific default data entry in the article. The item texts in examples 15 and 16 can be functionally-positionally segmented as article elements. They are directed at the lemma and form part of the lexicographic treatment presented in these articles.

As is the case in the examples from different versions of the MED different versions of other dictionaries also have different approaches to data that are article box candidates. In example 17 from the printed version of GW, an article box is allocated to the article of the lemma sign abnormity, giving descriptive data based on actual usage regarding the translation equivalents. This article box is also presented as a postcomment in this article.

abnorm'ity, wanstaltigheid; monstruositeit, monstrositeit.

Although the form given by the Afrikaanse Woordelys en Spelreëls as the only correct one is monstruositeit, we also recognise monstrositeit in this dictionary, since it is widely used in Afrikaans.

\section{Example 17 from $\mathbf{G W}$}

The online version of GW includes exactly the same data but not presented in a boxed form but as a mere item text in the postcomment position and directed at a non-lemmatic entry, i.e. a translation equivalent:

abnorm'ity, wanstaltigheid; monstruositeit, monstrositeit.

Although the form given by the Afrikaanse Woordelys en Spelreëls as the only correct one is monstruositeit, we also recognise monstrositeit in this dictionary, since it is widely used in Afrikaans.

Example 18 from GW (online) 


\section{Treatment or addressing?}

It is clear that the article boxes given in the preceding paragraphs do not participate in a relation of lemmatic or non-lemmatic addressing as defined in the existing metalexicographic literature. To a lesser degree this also applies to the pictorial illustrations discussed in a previous section of this paper. However, in each one of these articles the article box, with or without a topic or title, includes data relevant to the lemma and the pictorial illustrations also are integral parts of the data transfer employed to achieve the genuine purpose of the dictionary. The data in the article boxes as well as the pictorial illustrations form part of the treatment of the respective lemma signs.

Albeit that the participating entries seldom are the result of lexicographic textual condensation and therefore not items but mostly rather item texts, they fulfil the important criterion of participating in a relation where a form and information related to the form are brought together. As indicated earlier, this leads to the question as to whether the notion of addressing relations should be expanded to include some related lexicographic procedures.

\section{Online dictionaries}

The notion of addressing as introduced and defined by Wiegand has been directed at printed dictionaries. This applies to many aspects of the existing general theory of lexicography. One of the challenges facing modern-day metalexicographers is to adapt existing theory in such a way that it can also be applied to the planning and compilation of online dictionaries. A general theory is needed that is not medium specific. Some aspects of the old theory will still apply, some issues need to be adapted and some new features need to be introduced for online dictionaries. Lexicographers should negotiate the new approaches to online dictionaries to determine whether they could also influence the future of printed dictionaries.

Online dictionaries that have been planned and developed for the e-medium and are not second generation printed dictionaries typically display addressing relations but also much more occurrences of treatment relations that go beyond the traditional scope of addressing relations. The treatment of the word auto (=car) in the online elexiko dictionary shows a partially condensed article, with some screenshots displaying a lesser and other a higher occurrence of condensed entries. 


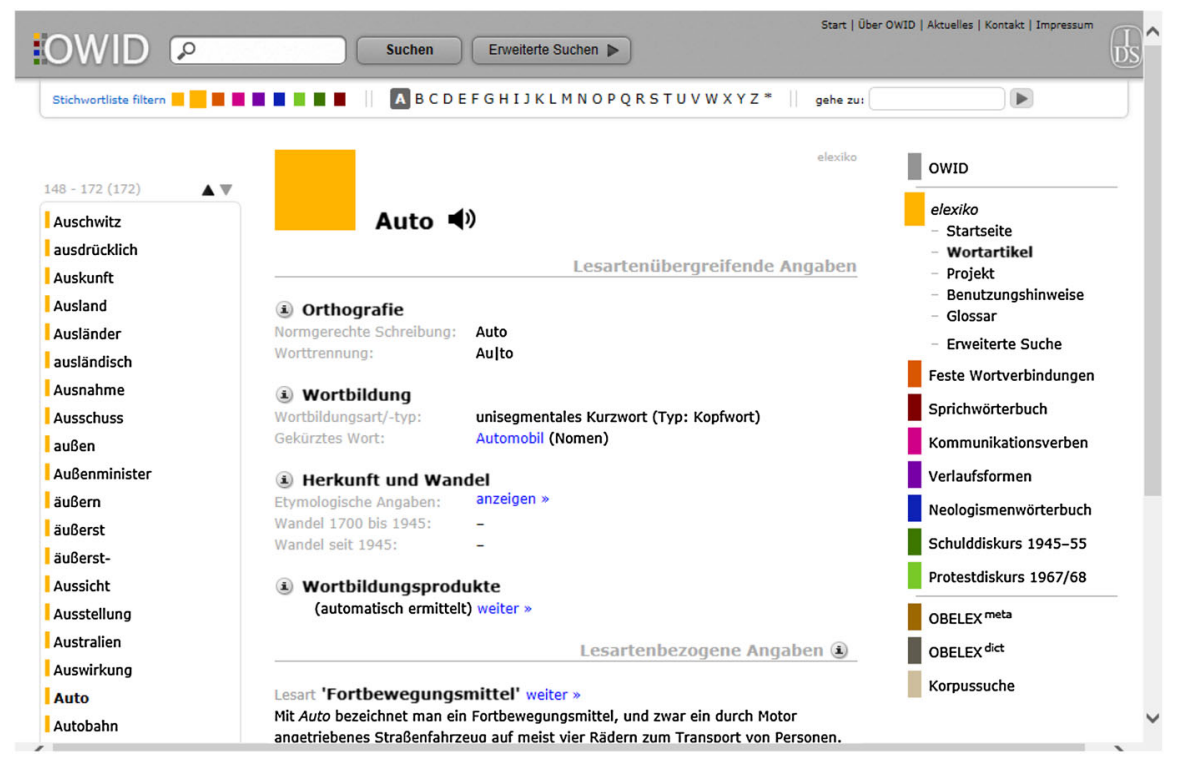

\section{Example 19 from elexiko}

In this opening screenshot of the article of the lemma auto the entries for the comment on form are given in a condensed way, albeit that the items are often preceded by a word indicating the specific data type, e.g.Worttrennung (=word division) in the article slot for orthography. This data type identifier is followed by the form "Aulto". The next screenshot, displaying a reduced article, gives among others the lemma sign and the paraphrase of meaning. This screenshot displays a mixed condensed article with the paraphrase of meaning presented as an item text and therefore not an addressed entry. 


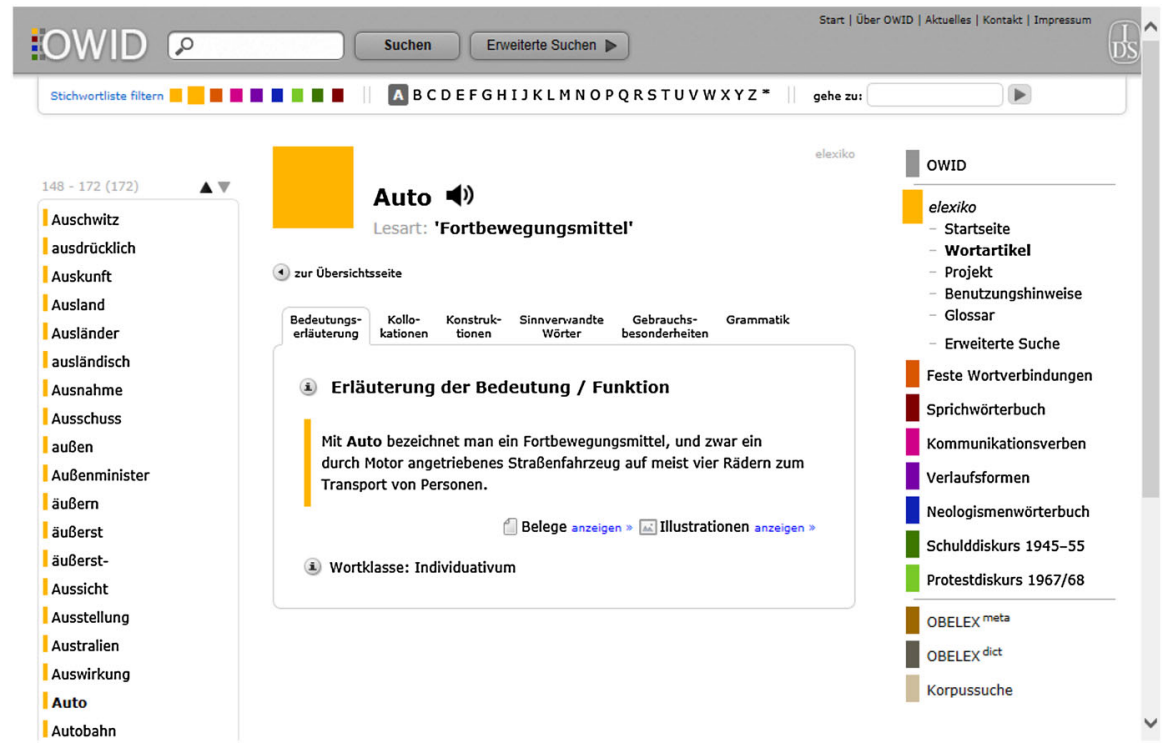

\section{Example 20 from elexiko}

The user then has a variety of options to proceed to different screenshots, representing different reduced articles with the lemma sign as guiding element and one or more other data-carrying entries displayed in each screenshot, e.g. pictorial illustrations in example 21, data regarding the use of the word in example 22 and data regarding collocations in example 23: 


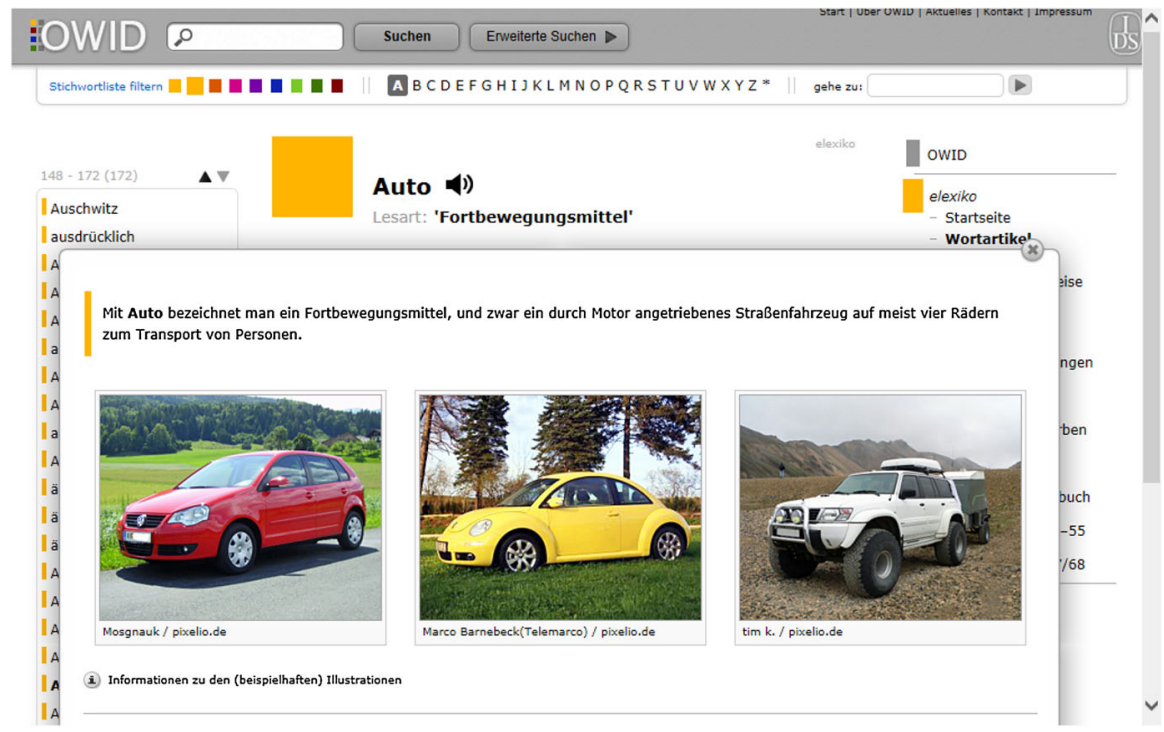

\section{Example 21 from elexiko}

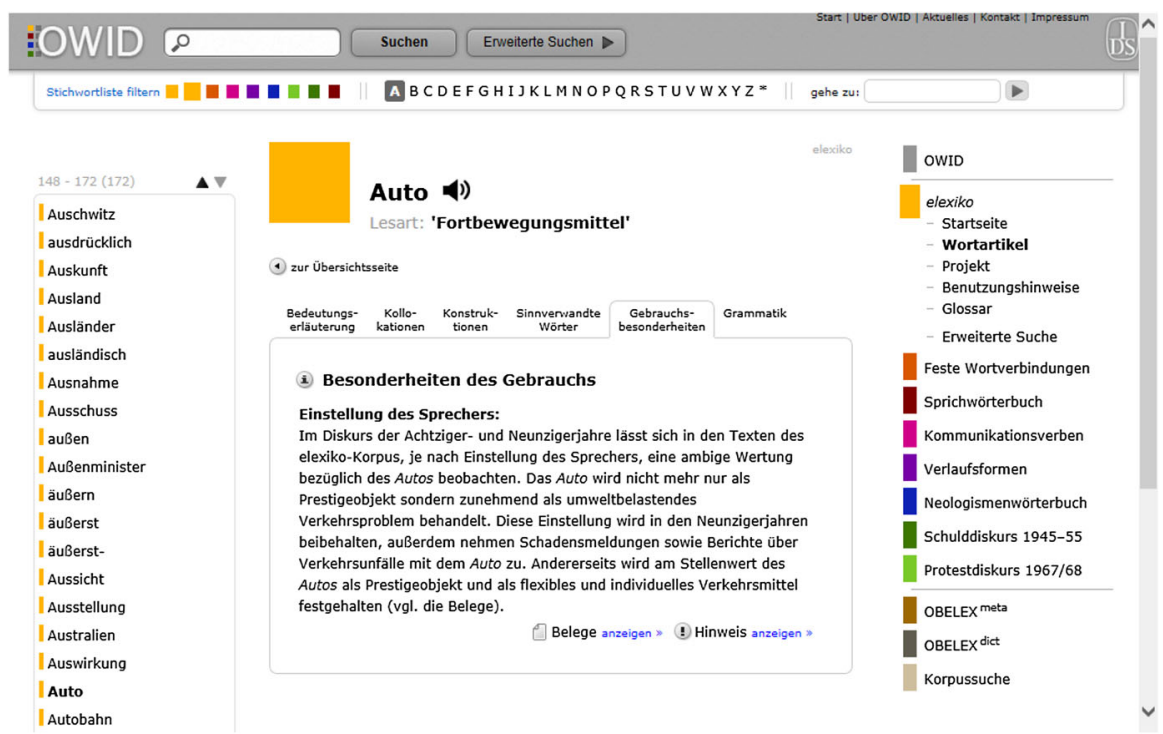

\section{Example 22 from elexiko}




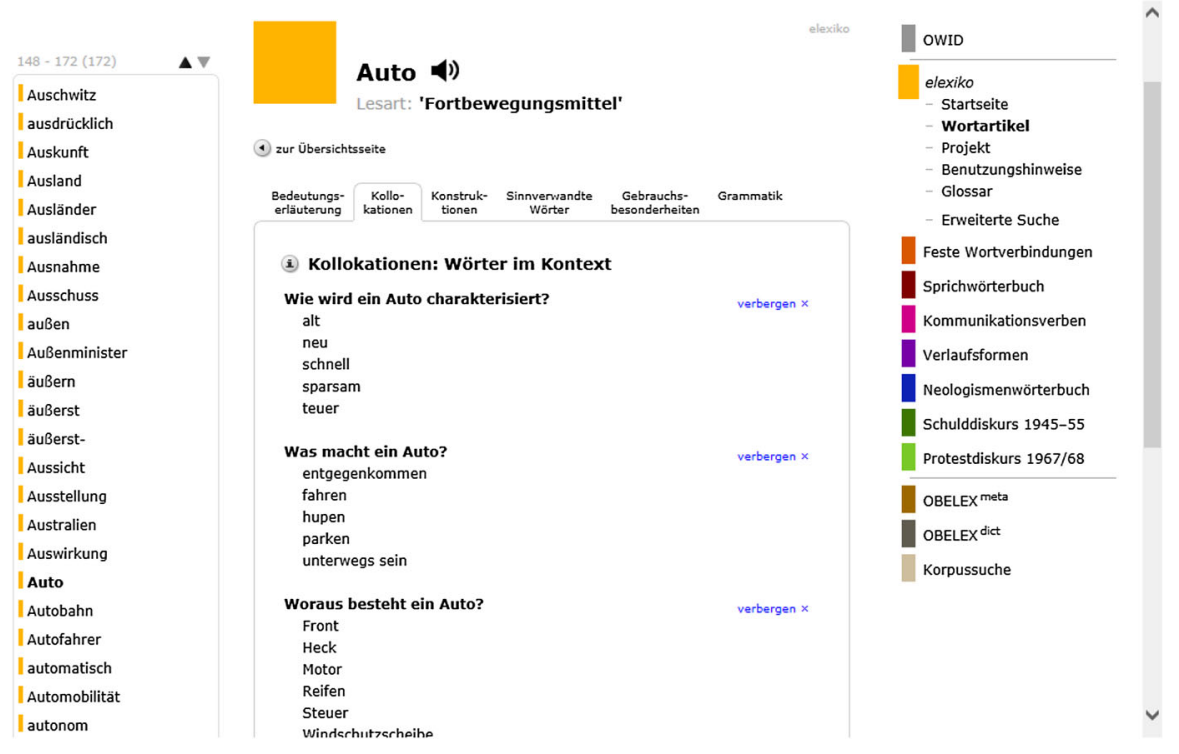

\section{Example 23 from elexiko}

These screenshots consistently display mixed condensed articles with some entries being part of addressing relations and others, merely on account of not being condensed, not being participants in a traditional addressing relation.

\section{Towards a new approach}

The current system of addressing, addressing relations and addressing structures needs to remain in place. The term addressing is highly appropriate. Besides the traditional interpretation and use of the terms addressing, addressing relations and addressing structure there might be a need for an expansion of the notion of addressing. The core criterion for addressing can be found in the original formulation by Hausmann and Wiegand (1989: 328), i.e. the bringing together of a form and information related to that form. The additional criteria of textual condensation and the accompanying non-naturalness of the lexicographic texts can be maintained but should be subordinate to the first criterion. As seen in a number of the preceding examples, the bringing together of a form and information related to that form goes beyond items as participating entries and also includes item texts, pictorial illustrations and even complete article boxes. In these examples data presented by items, item texts, pictorial illustrations, entries in article boxes, etc. as carriers of the data are directed at specific forms that function as their address. Where textual condensation does not play a role a comparable relation still exists between the form and the carrier with data directed at the specific form. Especially, in online dictionaries, a vast amount of entries do not participate in a traditional addressing relation but rather in relations between item texts and other article 
constituents presented in the screenshot structure as article components. This calls for an expanded application of the notion of addressing, henceforth referred to as secondary addressing. The term addressing can be used as superordinate for the terms primary addressing and secondary addressing with primary addressing adhering to the traditional criteria and secondary addressing expanding the notion to go beyond textual condensation and item status as prerequisites for addressed entries.

\section{In conclusion}

The development of lexicographic theory demands changes and adaptations to respond to changing needs. This implies that existing procedures and terms to describe these procedures need to be re-evaluated from time to time. In this paper, the notion of addressing has been examined and it has been found that the notion of addressing remains relevant and the term remains appropriate for certain lexicographic procedures. However, an expansion of the notion of addressing to make provision for numerous ways in which forms and information related to those forms are brought together, also in online dictionaries, results in the introduction of the terms primary and secondary addressing to negotiate the different procedures of addressing.

Acknowledgments This research is (a) conducted within the SeLA project (Scientific e-Lexicography for Africa), supported by a grant from the German Ministry for Education and Research, administered by the DAAD and (b) supported in part by the National Research Foundation of South Africa (Grant specific unique reference number (UID) 85434). The Grant holder acknowledges that opinions, findings and conclusions or recommendations expressed in any publication generated by the NRF supported research are those of the author, and that the NRF accepts no liability whatsoever in this regard.

\section{References}

\section{Dictionaries: printed dictionaries}

Du Plessis, M. 1993. Tweetalige aanleerderswoordeboek/Bilingual Learner's Dictionary (TAW). Cape Town: Tafelberg.

Eksteen, L.C. et al. (eds.) $1997^{14}$. Groot Woordeboek/Major Dictionary (GW). Cape Town: Pharos.

Gouws, R.H. et al. (eds.) 1994. Basiswoordeboek van Afrikaans (BWA). Pretoria: Van Schaik.

Hornby, A.S. $2010^{8}$. Oxford Advanced Learner's Dictionary of Current English (OALD ${ }^{8}$ ). Oxford: Oxford University Press.

Odendal, F.F., and R.H. Gouws. 2005. Verklarende Handwoordeboek van die Afrikaanse Taal (HAT). Cape Town: Pearson.

Sinclair, J. (ed.). 1987. Collins COBUILD English Language Dictionary (COBUILD). London: HarperCollins.

\section{Dictionaries: online dictionaries}

American Heritage Dictionary: http://ahdictionary.com/. elexico: http://www.owid.de/wb/elexiko/start.html. 
Longman Dictionary of Contemporary English (LDOCE): http://www.ldoceonline.com/dictionary/.

Macmillan English Dictionary: http://www.macmillandictionary.com/.

Oxford Dictionaries online: http://www.oxforddictionaries.com/.

Woordeboek van die Afrikaanse Taal: http://www.woordeboek.co.za.ez.sun.ac.za/.

\section{Other references}

AI-Kasimi, A.M. 1977. Linguistics and bilingual dictionaries. Leiden: E.J. Brill.

Barchudarow, L. 1979. Sprache und Ubersetzung. Probleme der allgemeinen und speziellen Übersetzungstheorie. Leipzig: Moskau.

Gouws, R.H. 1994. Ostensiewe adressering in vertalende woordeboeke. Lexikos 4: 61-85.

Gouws, R.H., and D.J. Prinsloo. 2005. Principles and practice of South African lexicography. Stellenbosch: SunMedia.

Gouws, R.H., and D.J. Prinsloo. 2010. Thinking out of the box-perspectives on the use of lexicographic text boxes. In Proceedings of the XIV Euralex International Congress, ed. A. Dykstra, and T. Schoonheim, 501-511. Leeuwarden: Fryske Akademy.

Gouws, R.H., and D.J. Prinsloo. 2014. Keeping house with pictures to depict culture and dictionary culture in bilingual dictionaries. Paper read at the 19th International Conference of AFRILEX.

Gouws, R.H., et al. (eds.). 2013. Dictionaries. An international encyclopedia of lexicography. Supplementary volume: recent developments with focus on electronic and computational lexicography. Berlin: De Gruyter.

Hancher, M. 1988. Bagpipe and distaff: interpreting dictionary illustrations. Dictionaries 10: 93-109.

Hausmann, F.J. 1977. Einführung in die Benutzung der neufranzösischen Wörterbücher. Tübingen: Max Niemeyer.

Hausmann, F.J., and H.E. Wiegand. 1989. Component Parts and Structures of Monolingual Dictionaries. In eds Hausmann, F.J. et al. 1989-1991: 328-360.

Hausmann, F.J. et al. (eds.). 1989-1991. Worterbücher. Dictionaries. Dictionnaires. An International Encyclopedia of Lexicography. Berlin: Walter de Gruyter.

Hupka, W. 1989. Wort und Bild. Die Illustrationen in Wörterbüchern und Enzyklopädien. Tübingen: Max Niemeyer.

Kromann, H.-P., et al. 1984. Überlegungen zu Grundfragen der zweisprachigen Lexikographie. In Germanistische Linguistik 3-6/84, ed. H.E. Wiegand, 159-238. Hildesheim: Georg Olms Verlag.

Louw, P.A., and R.H. Gouws. 1996. Lemmatiese en nielemmaties adressering in Afrikaanse vertalende woordeboeke. Suid-Afrikaanse Tydskrif vir Taalkunde 14: 92-100.

Stein, G. 1991. Illustrations in dictionaries. International Journal of Lexicography 4(2): 99-127.

Wiegand, H.E. 1989. Aspekte der Makrostruktur im allgemeinen einsprachigen Wörterbuch: alphabetische Anordnungsformen und ihre Probleme. In eds Hausmann, F.J. et al. 1989-1991: 371-409.

Wiegand, H.E. 2006. Adressierung in Printwörterbüchern. Präzisierungen und weiterführende Überlegungen. Lexicographica 22: 187-261.

Wiegand, H.E. 2011. Adressierung in der ein- und zweisprachigen Lexikographie. Eine zusammenfassende Darstellung. In Aus Ost und West, eds. W. Kürschner and M. Ringmacher, 109-234. Frankfurt: Lang.

Wiegand, H.E., and R.H. Gouws. 2011. Theoriebedingte Wörterbuchformprobleme und wörterbuchformbedingte Benutzerprobleme I Ein Beitrag zur Erweiterung der Theorie der Wörterbuchform. Lexikos 21: 232-297.

Wiegand, H.E, and R.H. Gouws. 2013. Addressing and addressing structures in printed dictionaries. In ed. R.H. Gouws et al. 2013: 273-314.

Wiegand, H.E and M. Smit. 2013. Microstructures in printed dictionaries. In ed. R.H. Gouws et al. 2013: 149-214. 